\title{
Effects of a multicomponent high intensity exercise program on physical function and health-related quality of life in older adults with or at risk of mobility disability after discharge from hospital: a randomised controlled trial
}

Sylvia Sunde ${ }^{1,2^{*}}$ D , Karin Hesseberg ${ }^{2}$, Dawn A. Skelton ${ }^{3}$, Anette Hylen Ranhoff ${ }^{2,4}$, Are Hugo Pripp ${ }^{5}$, Marit Aarønæs ${ }^{2}$ and Therese Brovold ${ }^{1}$

\begin{abstract}
Background: Many older people suffer from mobility limitations and reduced health-related quality of life (HRQOL) after discharge from hospital. A consensus regarding the most effective exercise-program to optimize physical function and HRQOL after discharge is lacking. This study investigates the effects of a group-based multicomponent high intensity exercise program on physical function and $\mathrm{HRQOL}$ in older adults with or at risk of mobility disability after discharge from hospital.

Methods: This single blinded parallel group randomised controlled trial recruited eighty-nine home dwelling older people (65-89 years) while inpatient at medical wards at a general hospital in Oslo, Norway. Baseline testing was conducted median 49 ( 25 percentile, 75 percentile) $(26,116)$ days after discharge, before randomisation to an intervention group or a control group. The intervention group performed a group-based exercise program led by a physiotherapist twice a week for 4 months. Both groups were instructed in a home-based exercise program and were encouraged to exercise according to World Health Organisation's recommendations for physical activity in older people. The primary outcome, physical performance, was measured by the Short Physical Performance Battery (SPPB). Secondary outcomes were 6-min walk test (6MWT), Berg Balance Scale (BBS), grip strength, Body Mass Index (BMI), and HRQOL (the Short-Form 36 Health Survey (SF-36)). Data were analysed according to the intention-to-treat principle. Between-group differences were assessed using independent samples t-test.
\end{abstract}

\footnotetext{
* Correspondence: Sylvia.Sunde@oslomet.no

${ }^{1}$ Institute of Physiotherapy, OsloMet - Oslo Metropolitan University (OsloMet),

PO Box 4, St. Olavs Plass, 0130 Oslo, Norway

2Diakonhjemmet Hospital, PO Box 23, Vinderen, 0319 Oslo, Norway

Full list of author information is available at the end of the article
}

(c) The Author(s). 2020 Open Access This article is licensed under a Creative Commons Attribution 4.0 International License, which permits use, sharing, adaptation, distribution and reproduction in any medium or format, as long as you give appropriate credit to the original author(s) and the source, provide a link to the Creative Commons licence, and indicate if changes were made. The images or other third party material in this article are included in the article's Creative Commons licence, unless indicated otherwise in a credit line to the material. If material is not included in the article's Creative Commons licence and your intended use is not permitted by statutory regulation or exceeds the permitted use, you will need to obtain permission directly from the copyright holder. To view a copy of this licence, visit http://creativecommons.org/licenses/by/4.0/ The Creative Commons Public Domain Dedication waiver (http://creativecommons.org/publicdomain/zero/1.0/) applies to the data made available in this article, unless otherwise stated in a credit line to the data. 
(Continued from previous page)

Results: The groups were comparable at baseline. Intention-to-treat analysis showed that the intervention group improved their functional capacity (6MWT) and the physical component summary of SF-36 significantly compared to the control group. No further between group differences in change from baseline to 4 months follow-up were found.

Conclusions: A high intensity multicomponent exercise program significantly improved functional capacity and physical HRQOL in older adults with or at risk of mobility disability after discharge from hospital. The study suggests that this population can benefit from systematic group exercise after hospital-initial rehabilitation has ended.

Trial registration: ClinicalTrials.gov. NCT02905383. September 19, 2016.

Keywords: Hospitalisation, Physical function, Health-related quality of life, Older adults, Exercise interventions

\section{Background}

Reduced physical function with increasing age can have tremendous negative consequences, both for the older individuals, their families and the society, hence preserving physical function, independence and HRQOL in older adults is central to the global response to population ageing [1]. Hospitalization often exacerbates the effects of ageing on physical function, and many older people suffer from mobility limitations and reduced HRQOL after discharge [2-5].

The literature on interventions aiming to preserve physical function [6-9] and HRQOL in the general population is vast, and interventions should include endurance, strength, balance and flexibility exercises [10]. To preserve good health, the World Health Organization (WHO) recommends people aged 65 years and older to engage in cardiorespiratory exercise training of moderate intensity at least $150 \mathrm{~min}$ per week, or at least $75 \mathrm{~min}$ if the intensity is vigorous [11]. A combination of moderate- and vigorous-intensity exercise is just as good, and bouts of aerobic exercise lasting at least 10 min count in the weekly summary. In addition, muscle-strengthening exercises, involving major muscle groups, should be conducted at least twice a week. Further, older adults with poor mobility are recommended to perform physical activity to enhance balance and prevent falls on at least 3 days per week. Those who are not able to meet the recommendations due to health conditions are encouraged to engage in as much physical activity as their abilities and conditions allow [11].

Physical activity and exercise therapy after hospitalization of geriatric patients has shown to be feasible [12] and could be an important means to help counteract the challenges associated with an ever-growing older population [13-17]. Nevertheless, a consensus regarding the most effective exercise-program to optimize physical function and HRQOL after discharge from hospital is lacking [18-20]. However, the rehabilitation sessions should be supervised to increase adherence [12] and reduce falls [21]. Furthermore, interventions with high intensity has proven somewhat superior to interventions with lower intensity in terms of improving physical function in community-dwelling older adults with impaired mobility, physical disability and/or multi-morbidity [22]. A recent systematic review on effectiveness of interventions to prevent pre-frailty and frailty progressions in older adults found that the group-setting was crucial to the effect of physical exercise programs [23].

By targeting older people with or at risk of mobility disability while inpatient, the vicious circle of inactivity and reduced physical function and HRQOL often experienced after discharge for older people could be counteracted [15]. Therefore, the objective of this study is to examine the effects of a high intensity multicomponent group-based intervention on physical function and HRQOL in older adults with or at risk of mobility disability after discharge from hospital.

\section{Methods}

\section{Study design}

A parallel group randomised controlled trial with one intervention group and one control group, allocated on a 1:1 ratio. The CONSORT 2010 Statement are followed in our report [24]. See Additional file 5 for CONSORT 2010 Checklist. The associations between the participants baseline scores on HRQOL (SF-36) and physical function (SPPB) is submitted as an independent article but it is still not accepted for publication.

\section{Setting and participants}

Participants were initially recruited while acutely admitted to a general hospital in Oslo, Norway. Recruitment was based on registration lists of patients admitted at four medical wards. The recruitment period was from September 2016 to May 2019. Baseline testing was conducted after discharge and when the participants had completed hospital-initial rehabilitation. Participants provided written informed consent.

Inclusion criteria: age $\geq 65$ years, live independently in the community, be at risk of mobility disability with a Short Physical Performance Battery (SPPB) score of $<10$ while inpatient [25], ambulate independently (walking aid permitted), and understand Norwegian language. 
Further, they had to be assessed by a doctor (A.H.R or M.A.) as eligible for the intervention according to the standards from the American Heart Association [26].

Exclusion criteria: moderate or severe cognitive disorder (Score on Mini Mental State Examination <20) [27], life expectancy less than 8 months, exercise regularly more than twice a week at a fitness centre or in a structured exercise program.

All participants received routine care, discharge planning, follow-up care and rehabilitation normally provided.

Changes to methods after trial commencement: we started the study with age $\geq 70$ as an inclusion criterion but altered it to $\geq 65$ after 1 year as an attempt to increase the recruitment speed. Further, the intervention was planned to be performed in cooperation with physiotherapists working in primary health care and in localities offered by three different city districts in Oslo Municipality, to be close to the participants homes and facilitate implementation of the intervention after the study had ceased. However, due to poor recruitment rate that made it counterproductive to run the intervention at three different sites, we decided to merge the groups and offer the intervention at the hospital gym.

\section{Intervention}

The intervention group performed a group-based highintensity multicomponent exercise program twice a week for four to 5 months, maximum 32 sessions or 5 months. The intervention was based on the Norwegian Ullevaal model [28] and the Swedish High-Intensity Functional Exercise Program (the HIFE program) [29, 30]. The intervention was led by one or two physiotherapists, in groups of 2-10 participants. The participants performed two strength exercises for the lower limbs (standing-up from sitting in a parallel stance and forward lunges), six balance exercises (walking forward on a line on a flat surface, heel raises, reaching for an object in various directions, one leg standing, step-over, and throwing and catching a ball), in addition to trunk rotation while seated. The exercise program is described in detail in Additional file 1 , in accordance with the CERTrecommendations [31]. The exercises were accompanied by music, and conducted in the same sequence each session, following a detailed manual designed in accordance to a 53-min long playlist.

The intensity of the exercise was self-paced, but the participants were encouraged to exercise progressively, with a gradual approach to high intensity. Highintensity strength exercises were defined as two sets of 8-12 repetition maximum (RM) and the balance exercises were performed near the limits of maintaining postural stability [30]. The exercises were adjusted according to the participants' health status, in each session. The participants wore weighted belts around the waist for the two strengthening exercises, loaded with a maximum of $12 \mathrm{~kg}$. Each session also contained three 6-9 min bouts of high intensity endurance training, where the participants were encouraged to exercise with a Borgs exertion of 15-18 [32] the last 3-4 min, interspersed with flexibility exercises, in addition to the strength and balance exercises. Adverse events were registered in the following four categories; falls, cardiovascular events, musculoskeletal injuries and health care utilization [33].

Both the intervention group and the control group were given written information in Norwegian on the recommendations from the WHO on physical activity for people aged 65 and above [11], and they were encouraged to adhere to this recommendations (see Additional file 2). Both groups were instructed in a homebased exercise program to improve strength of the lower extremities and balance (see Additional file 3). This exercise program was developed by physiotherapists from the Norwegian University of Science and Technology (NTNU) and Trondheim Municipality in 2016, founded by the Norwegian Directorate of Health [34]. The participants were encouraged to perform the exercises at least 3 days a week. These exercises were also included in the multicomponent high intensity exercise intervention, so the intervention group was encouraged to perform the exercises at least once a week at home if they had attended the intervention group twice that week.

\section{Outcome measures}

Information about the participants' age, sex, living status (alone or with someone), education, hospital discharge diagnoses, number of comorbidities at the time of discharge, and length of stay were recorded from the participants` hospital records and by asking the participants. In addition, the participants filled out the International Physical Activity Questionnaire - Short form (IPAQ-SF) at home before baseline testing [35]. Assessments were conducted at a hospital outpatient clinic, by trained research assistants blinded to the group allocation, at baseline and following the intervention at 4 months.

\section{Primary outcome measure}

Physical performance was measured using the Short Physical Performance Battery (SPPB), a performance based test that evaluates balance (ability to stand with feet together in side-by side, semi tandem and tandem positions), functional mobility (gait speed; time to walk $4 \mathrm{~m}$ in preferred tempo) and muscle strength (time to rise from a chair and return to the seated position five times) [36]. The sum score ranges from 0 to 12 (worse-best). 


\section{Secondary outcome measures}

Functional capacity was measured by the six-minute walk test [37], performance-based balance by Berg Balance Scale (BBS) [38], muscle strength (grip strength) by Jamar dynamometer [39], weight and Body Mass Index (BMI) by a Tanita BC-418 Body Composition Analyzer for the participants without a pacemaker (contraindication). An electronic body scale was used for patients with a pacemaker, and BMI was calculated (weight in kilograms divided by height in meters squared). Finally, HRQOL was measured by the Medical Outcome Study 36 Item Short-Form Health Survey, version 2 (SF-36) [40].

\section{Sample size}

A medium meaningful difference between the groups in change of SPPB was defined to 0.75 points with an expected standard deviation of 1.48 points [41]. To obtain $80 \%$ statistical power with a $5 \%$ significance level, 126 participants, 63 in each group, was needed. We aimed to include at least 150 participants, to compensate for potential drop-outs.

\section{Randomisation}

Allocation to an intervention group or a control group was done after baseline testing, based on a computergenerated permuted block randomization scheme. Each block contained between four to ten subjects. TB and $\mathrm{KH}$ administered the scheme, and sealed envelopes were used.

\section{Statistical analyses}

Statistical analyses were conducted with the IBM SPSS version 25 (SPSS Inc., Chicago, IL). $P$-values $<0.05$ were considered statistically significant and all tests were twosided. The normality of the distributions was examined graphically by histograms and Q-Q plots, and by comparing the mean with the median. Data are described as means and standard deviations (SD) for normally distributed continuous variables, and median and quartiles (25, 75) for a continuous variable that was skewed (length of stay). Categorical variables are described with proportions and percentages.

Between group differences in change from baseline to follow-up were analysed using the independent samples t-test according to the intention to-treat (ITT) principle. The ITT analyses were also conducted on a dataset where missing values were substituted by using the multiple imputations function in SPSS [42]. Floor and ceiling effects were considered when more than $20 \%$ of the participants achieved the lowest or highest score. Effect size was calculated, and interpreted according to the guidelines proposed by Cohen [43]; $.2=$ small effect, $.5=$ medium effect and $.8=$ large effect.

\section{Research ethics}

The Regional Ethics Committee for Medical Research approved the study (REK 2015/2432), and the trial was registered at ClinicalTrials.gov in September 2016, NCT02905383. The first patient was included in September 2016.

\section{Results}

\section{Flow of participants}

The flow of the study participants can be seen in a flow diagram (Fig. 1). Five hundred and thirty-eight participants were screened for eligibility, of which 89 were included. One hundred and ninety-four did not meet the inclusion criteria, and 255 refused to participate. The most common reasons for declining to participate were regular physical training at fitness centre, too busy helping kin or others, did not want regular appointments twice a week, traveling time/logistics and spending time abroad. Recruitment stopped before the sample size target was reached due to a slow recruitment rate and a limited timeframe. Baseline testing was conducted median 49 ( 25 percentile, 75 percentile) $(26,116)$ days after discharge. Forty-five participants were randomly allocated to the intervention group and 44 to the control group. The groups were comparable at baseline. One man in the intervention group withdrew from the study and requested that we deleted his data. Additional twelve participants $(28.9 \%$ in total) in the intervention group and thirteen participants (29.6\%) in the control group were lost to follow-up.

Twenty-six $(89.7 \%)$ of the 29 participants with data from the four-month follow-up attended at least 16 $(50 \%)$ of the group-based sessions and were defined as adherent to the intervention. These 26 participants attended mean (SD) 28.1 (3.9) sessions, while the mean (SD) for the total 29 participants was 25.5 (8.6) sessions. Reasons for not attending the sessions were experiencing decline in health or re-hospitalisation. The Borg scale and repetition maximum (RM) were used to encourage the participants to achieve high intensity during the endurance and strength exercises respectively. For the balance exercises the base of support was reduced and the ball was thrown in a more challenging manner. However, adherence regarding actual intensity accomplished was not measured.

Adverse events during exercise: the physiotherapists leading the intervention group reported three falls without injury. One participant was confused (delirium) at a session and was admitted to the hospital.

\section{Participant characteristics}

Table 1 shows the baseline characteristics for the total sample and for the intervention group and the control group separately. There were no statistically significant 


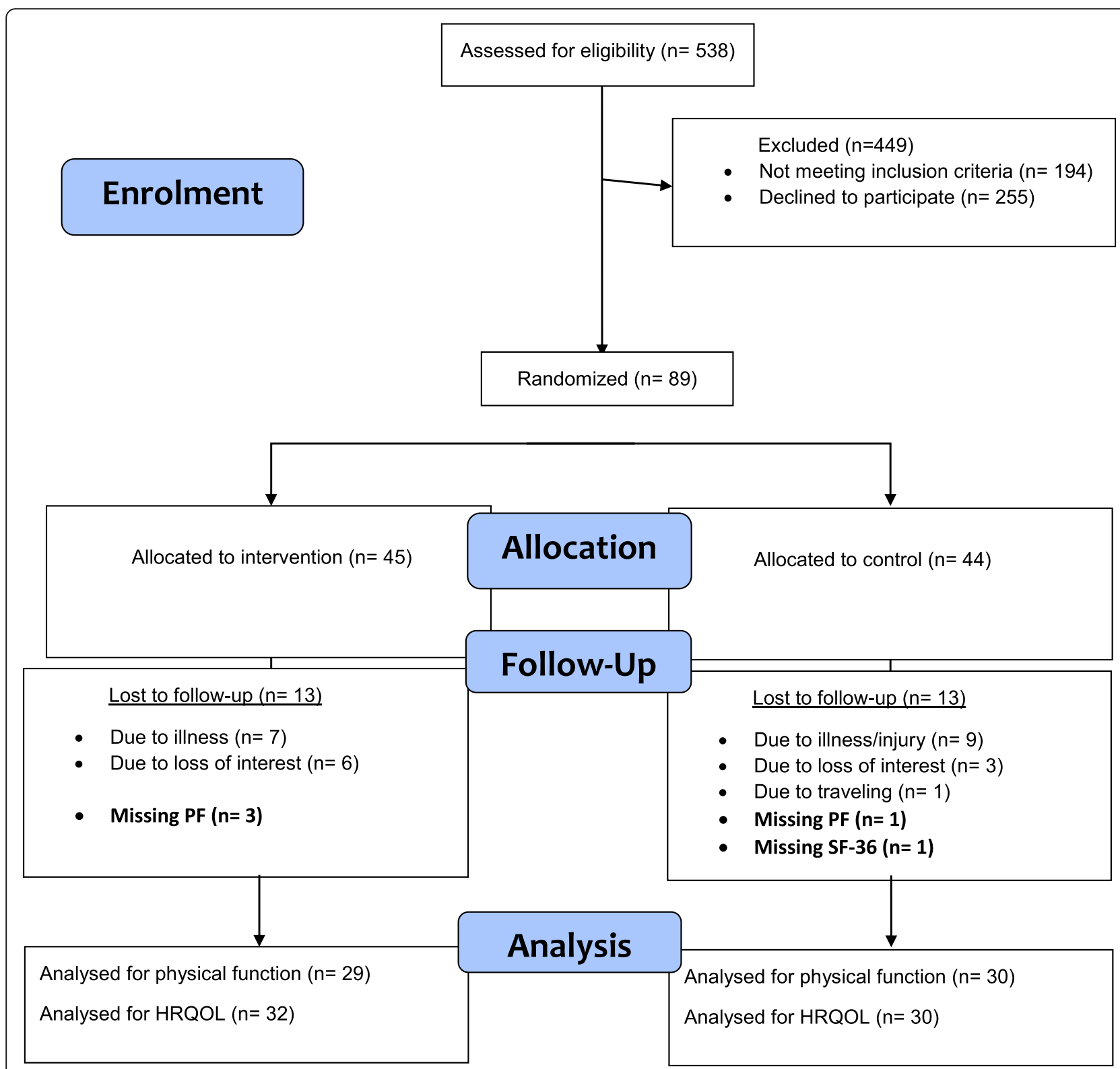

Fig. 1 Flow diagram through 4 months follow-up. Missing PF means that the participant did not perform the tests for physical function but filled out the self-reported questionnaire (SF-36). Missing SF-36 means that the participant performed the tests for physical function but did not fill out SF-36

differences in the participants who were included in the study and those who were excluded regarding sex and age. The participants who were lost to follow-up scored significantly worse on SPPB $(p=0.026)$ and six min walk test $(p=0.033)$ at baseline than the rest of the sample. No other significant differences were found in characteristics or outcome measures between completers/dropouts at baseline.

Eighty-one patients (92\%) had two or more comorbidities. Half of the participants walked less than $400 \mathrm{~m}$ on the 6 -min walk test. Sixty percent scored $\leq 9$ points on SPPB, scores ranged from 4 to 12 . No floor- and ceiling effects occurred at baseline. At 4 months follow-up, $22.7 \%$ of the participants in the intervention group scored 12 on SPPB and 56 on BBS.

\section{ITT analyses}

Table 2 presents the ITT analyses. No significant between group difference was found in the primary outcome: SPPB sum score (mean difference 0.8 points, $95 \%$ CI $-0.3-1.8, p=0.151$, effect size $=0.38$ ). The results for the three subtests of SPPB can be seen in Additional file 6 . There was a significant between group difference in favour of the intervention group on 6-min 
Table 1 Characteristics of the study sample. Means, standard deviations (SD), numbers and percentages

\begin{tabular}{|c|c|c|c|}
\hline Characteristics & Total $(N=88)$ & Intervention group $(n=44)$ & Control group $(n=44)$ \\
\hline Age in years, mean (SD) & $78.3(5.5)$ & $78.6(5.7)$ & $77.9(5.2)$ \\
\hline Sex, female n (\%) & $43(48.9)$ & $17(38.6)$ & $26(59.1)$ \\
\hline Living alone, n (\%) & $45(51.1)$ & $22(50.0)$ & $23(52.3)$ \\
\hline \multicolumn{4}{|l|}{ Education, n (\%) } \\
\hline Less than bachelor's degree & $35(39.8)$ & $12(27.3)$ & $23(52.3)$ \\
\hline Bachelor's degree & $32(36.4)$ & $20(45.5)$ & $12(27.3)$ \\
\hline More than bachelor's degree & $21(23.9)$ & $12(27.3)$ & $9(20.5)$ \\
\hline Length of stay, in days, median (IQR) & $2(1-4)$ & $2(1-4.8)$ & $3(1-4)$ \\
\hline Number of comorbidities, mean (SD) & $4.7(2.3)$ & $4.2(2.5)$ & $4.8(2.1)$ \\
\hline \multicolumn{4}{|l|}{ Hospital admission diagnosis (ICD-10), n (\%) } \\
\hline Mental and behavioral disorders & $4(4.5)$ & $2(4.5)$ & $2(4.5)$ \\
\hline Diseases of the nervous system & $5(5.7)$ & $2(4.5)$ & $3(6.8)$ \\
\hline Diseases of the eye and adnexa/ear and mastoid process & $6(6.8)$ & $5(11.4)$ & $1(2.3)$ \\
\hline Diseases of the circulatory system & $31(35.2)$ & $16(36.4)$ & $15(34.1)$ \\
\hline Diseases of the respiratory system & $14(15.9)$ & $8(18.2)$ & $6(13.6)$ \\
\hline Diseases of the musculoskeletal system and connective tissue & $5(5.7)$ & $4(9.1)$ & $1(2.3)$ \\
\hline Diseases of the genitourinary system & $9(10.2)$ & $2(4.5)$ & $7(15.9)$ \\
\hline Other diseases & $14(15.9)$ & $5(11.4)$ & $9(20.5)$ \\
\hline Fall since discharge, $\mathrm{n}(\%)$ & $25(28.4)$ & $11(25.0)$ & $14(31.8)$ \\
\hline \multicolumn{4}{|l|}{ Physical function: } \\
\hline Short Physical Performance Battery, mean (SD) ${ }^{a}$ & $8.7(2.3)$ & $8.6(2.3)$ & $8.9(2.2)$ \\
\hline Gait speed m/s, mean (SD), $n=85$ (42 int. group and 43 cont. group) & $0.8(0.2)$ & $0.8(0.2)$ & $0.8(0.2)$ \\
\hline Grip strength kg, mean (SD) & $26.3(9.1)$ & $26.8(8.7)$ & $25.8(9.5)$ \\
\hline Berg Balance Scale, mean (SD) ${ }^{a}$ & $48.9(6.8)$ & $48.8(6.6)$ & $48.9(7.1)$ \\
\hline 6-min walk test m, mean (SD) & $387.4(115)$ & $378.8(109.8)$ & $396.1(120.7)$ \\
\hline Body mass index, mean (SD) & $26.9(5.4)$ & $26.1(5.4)$ & $27.8(5.4)$ \\
\hline \multicolumn{4}{|l|}{ International physical activity questionnaire (IPAQ), $n=69$} \\
\hline High, n (\%) & $7(10.2)$ & $4(10.8)$ & $3(9.4)$ \\
\hline Moderate, n (\%) & $25(36.2)$ & $14(37.8)$ & $11(34.4)$ \\
\hline Low, n (\%) & $37(53.6)$ & $19(51.4)$ & $18(56.3)$ \\
\hline \multicolumn{4}{|l|}{$\underline{\text { Health related quality of life (SF-36): }}$} \\
\hline Physical functioning, $n=88$ (44 int. group and 44 cont. group) & $58.9(23.3)$ & $57.1(22.7)$ & $60.7(24.0)$ \\
\hline Role physical, $n=83$ (41 int. group and 42 cont. group) & $47.0(27.8)$ & $42.9(27.5)$ & $51.0(27.9)$ \\
\hline Bodily pain, $n=83$ (42 int. group and 41 cont. group) & $56.6(25.9)$ & $55.8(28.4)$ & $57.4(23.5)$ \\
\hline General health, $n=85$ (43 int. group and 42 cont. group) & $52.2(21.6)$ & $50.5(21.2)$ & $54.1(22.2)$ \\
\hline Vitality, $n=86$ (43 int. group and 43 cont. group) & $44.9(17.5)$ & $44.8(15.5)$ & $44.9(19.6)$ \\
\hline Social functioning, $n=87$ (44 int. group and 43 cont. group) & $67.5(28.1)$ & $67.3(26.9)$ & $67.7(29.5)$ \\
\hline Role emotional, $n=83$ (43 int. group and 40 cont. group) & $59.4(23.2)$ & $62.2(21.9)$ & $56.5(24.4)$ \\
\hline Mental health, $n=85$ (43 int. group and 42 cont. group) & $67.7(14.4)$ & $66.7(15.2)$ & $68.7(13.6)$ \\
\hline Physical component summary, $n=79$ (40 int. group and 39 cont. group) & $39.0(10.1)$ & $37.3(10.5)$ & $40.7(9.5)$ \\
\hline Mental component summary, $n=79$ (40 int. group and 39 cont. group) & $47.7(8.1)$ & $48.0(8.7)$ & $47.3(7.5)$ \\
\hline
\end{tabular}

$N$ number of individuals, ICD International Classification of Disease, BMI Body Mass Index, calculated using the formula weight in kilograms divided by height in meters squared.

SF-36 = the medical Outcome 36 -Item Short Form Survey

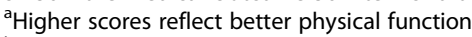

${ }^{b}$ Higher scores reflect better HRQOL 
Table 2 Results at 4-month follow-up and effect of intervention based on intention-to-treat analysis

\begin{tabular}{|c|c|c|c|c|c|c|}
\hline & $\begin{array}{l}\text { Intervention group } \\
4 \text { months, mean (SD) }\end{array}$ & $\begin{array}{l}\text { Control group } \\
4 \text { months, mean (SD) }\end{array}$ & $\begin{array}{l}\text { Mean between } \\
\text { group difference }\end{array}$ & $\begin{array}{l}95 \% \text { confidence } \\
\text { interval }\end{array}$ & $P$ value & $\begin{array}{l}\text { Effect } \\
\text { size }^{d}\end{array}$ \\
\hline \multicolumn{7}{|l|}{ Physical function } \\
\hline $\mathrm{SPPB}^{\mathrm{b}}$ & $9.3(2.8)$ & $9.3(2.7)$ & 0.8 & $-0.3-1.8$ & 0.151 & 0.38 \\
\hline 6-min walk test $(\mathrm{m})$ & $419.3(122.9)$ & $412.7(138.3)$ & 30.9 & $2.1-59.8$ & 0.036 & 0.56 \\
\hline Berg Balance Scale & $50.0(7.0)$ & $50.5(7.7)$ & -0.6 & $-2.2-0.9$ & 0.402 & 0.22 \\
\hline Grip strength (kg) & $28.0(8.3)$ & $26.5(9.8)$ & 1.1 & $-0.5-2.7$ & 0.178 & 0.36 \\
\hline BMI & $25.9(3.5)$ & $27.1(5.9)$ & 0.1 & $-0.4-0.6$ & 0.672 & 0.12 \\
\hline \multicolumn{7}{|l|}{$\underline{\text { HRQOL (SF-36) }}$} \\
\hline $\mathrm{PCS}^{\mathrm{C}}$ & $42.9(11.2)$ & $38.5(10.3)$ & 7.1 & $3.1-11.1$ & 0.001 & 0.94 \\
\hline $\mathrm{MCS}^{\mathrm{C}}$ & $48.4(8.1)$ & $49.8(7.8)$ & -0.7 & $-4.0-2.7$ & 0.694 & 0.10 \\
\hline
\end{tabular}

SPPB Short Physical Performance Battery, BMI Body Mass Index, calculated using the formula weight in kilograms divided by height in meters squared, SD Standard deviation, HRQOL Health Related Quality of Life, SF-36 the medical Outcome 36 -Item Short Form Survey, PCS Physical component summary, MCS Mental component summary. Statistically significant $p$-values are in bold. The level of significance was set at 0.05

${ }^{a}$ Mean between group difference refers to difference between outcome at baseline and 4-month-follow up

${ }^{b}$ Higher scores reflect better physical function

'Higher scores reflect better HRQOL

${ }^{d}$ Effect size $=$ Cohen's d

walk (mean difference $30.9 \mathrm{~m}, 95 \%$ CI 2.1-59.8 m, $p=$ 0.036 , effect size $=0.56$ ) and the physical component summary of SF-36 (mean difference 7.1 points, 95\% CI 3.1-11.1, $p=0.001$, effect size $=0.94$ ). No statistically significant differences between the groups were found in the mental component summary of SF-36, Berg Balance Scale, grip strength or BMI (Table 2). ITT analyses conducted on the dataset with imputations gave similar findings with respect to the between group differences (Additional file 4).

\section{Discussion}

Results from this study showed that a high intensity multicomponent exercise program did not improve physical performance measured by SPPB in older adults with or at risk of mobility disability after discharge from hospital. However, improvements in functional capacity measured by $6 \mathrm{MWT}$ and physical HRQOL were found. Further, this exercise program can be considered safe for this population since no serious adverse events occurred.

The lack of statistically significant difference in change between the groups in the primary outcome SPPB can be due to both the intervention group and the control group receiving instruction in home-based exercises and recommendations about physical activity for people aged $65+$. However, this possible explanation does not match the significant difference in 6MWT. Another possible reason may be that SPPB is not as sensitive to change as the 6MWT [44]. Furthermore, the insufficient sample size may have caused a type 2 error, where a difference between the groups cannot be detected [45]. This also implies for all the secondary outcomes where no statistically significant difference in change between the groups was found. The lack of significant difference in SPPB and Bergs Balance Scale could possibly be attributed to a ceiling effect, since $22.7 \%$ of the participants in the intervention group achieved the highest possibly score after the intervention on both tests. Even though the between group difference in change in SPPB score was not statistically significant, a change of 0.8 points can be considered clinically meaningful [41].

In this study, the mean between group difference in change from baseline to four-month follow-up in distance walked in six minutes was 30.9 (2.1-59.8) meters. This is considered a small meaningful change in older people [41], and hence of clinical relevance. The amount of change in SF-36 that constitutes a meaningful change in older people has not been established, but a change of half a standard deviation may serve as a default value for important changes in HRQOL in different populations [46]. Hence, the change of 7.1 points in PCS in the present study can be considered clinically important.

The study sample had generally low scores on SPPB at baseline, compared to age-matched Norwegian reference values [44]. Further, the participants scored generally worse on HRQOL (SF-36) at baseline when compared to a normative sample of older people aged 70-80 [47]. This reinforce that older patients with or at risk of mobility disability while hospitalized have increased risk of transitioning to frailty, and possibly reduced independence and HRQOL. Targeting this group of older people in interventions aiming to improve physical function and HRQOL is, thus, of paramount importance in order to maintain their independence and HRQOL.

The present study extends the work done by Brovold et al., a randomised controlled trail comparing an aerobe 
high intensity exercise program with usual care in a Norwegian sample of 115 independent older people recently discharged from hospital [4]. Our results are in line with this study that also found a significant between group difference in 6 min walk test. However, whereas Brovold et al. excluded participants who could not complete the Timed up and go test within $20 \mathrm{~s}$, we included mobility limited participants with a score $\leq 9$ points on the SPPB. Older adults with or at risk of mobility disability after discharge from hospital is a group of people that is often excluded from studies, despite being at high risk for many negative outcomes.

This study adds to previous research suggesting that group-based exercises can be beneficial and safe to older people after discharge from hospital $[15,20]$. This study brings new knowledge about the effect of an exercise program on functional capacity and physical HRQOL to the population of older adults with or at risk of mobility disability after discharge from hospital. According to McKelvie et al., such studies are urgently needed [18].

The most important limitation of this study is the low number of participants. We experienced that it was difficult to recruit participants to the study, a large portion of the eligible patients declined to participate, and we did not accomplish the estimated sample size. As already mentioned, the lack of power might have prevented significant findings regarding between group changes. According to Buurman [48] the problem of declining participants is frequently encountered in studies recruiting acutely hospitalized older people. The inclusion rate might have implications for the generalizability of the study results, but we found no significant differences in age and sex between those who declined participation and those who accepted inclusion.

The difficulties of recruiting patients could be an indication that a major part of the targeted group should be offered another alternative when discharged from hospital. In accordance with the most common reasons for declining to participate, offering a more flexible program with drop-in classes could be an alternative. Another option could be to offer a supervised home-based exercise program to the patients who declined to participate due to traveling time/logistics. However, the effect of a supervised high intensity multicomponent home-based exercise program aiming to increase physical function and HRQOL has to the best of our knowledge not been studied in this population and should be tested in a feasibility study and further in a randomized controlled trial.

The participants who were included accepted to participate in a multicomponent high-intensity exercise trial aiming to increase their physical function and HRQOL. This may have caused selection-bias of the most fit and motivated patients [49], and limit the generalisation of the results. Further, the participants were recruited from only one hospital in Oslo, and the study sample may not be representative for the general population of older people in Norway.

Finally, interventions that start while the older adult is inpatient and continue after discharge is recommended for this population [50]. The short length of stay in Norway makes that challenging to accomplish, but further studies should try to start as early as possible after admission.

\section{Conclusion}

In conclusion, the high-intensity multicomponent exercise program significantly improved functional capacity and physical HRQOL in this sample of older people with or at risk of mobility disability after discharge from hospital.

\section{Supplementary information}

Supplementary information accompanies this paper at https://doi.org/10. 1186/s12877-020-01829-9.

Additional file 1. The high intensity multicomponent exercise program described according to the Consensus on Exercise Reporting Template (CERT) guidelines.

Additional file 2. Information sheet: recommendations on physical activity for people 65 years and above

Additional file 3. Home exercises.

Additional file 4. Results at 4-month follow-up and effect of intervention based on intention-to-treat analysis with multiple imputations.

Additional file 5. CONSORT 2020 Checklist

Additional file 6 . The subcomponents of SPPB

\section{Abbreviations}

HRQOL: Health-Related Quality of LIFE; SPPB: Short Physical Performance Battery; 6MWT: 6-min walk test; BBS: The Berg Balance Scale; BMI: Body Mass Index; SF-36: The Medical Outcome Study 36 Item Short-Form Health Survey; WHO: World Health Organization; RM: Repetition Maximum; NTNU: Norwegian University of Science and Technology; IPAQ-

SF: International Physical Activity Questionnaire - Short form; ITT: IntentionTo-Treat; PF: Physical function; SD: Standard Deviations; N: Numbers; ICD: International Classification of Disease

\section{Acknowledgements}

We are sincerely grateful to the participants for their contribution to the study, and to the physiotherapists involved in testing the participants and/or leading the intervention. In addition, we would like to thank all the employees at Diakonhjemmet hospital who contributed to the study in one way or another, and the physiotherapists and leaders in the city districts for their willing and efforts to help.

\section{Authors' contributions}

TB and SS initiated the study. All authors contributed substantial to the study design and planning. AHR and MA assessed the participants eligibility for the intervention. SS managed the data collection, conducted the data analysis and wrote the first draft of the manuscript. TB and AHP contributed with statistical plan and advice. $\mathrm{KH}$ and DAS substantively revised the manuscript. All authors are collectively responsible for the interpretation of results, critical reviews of the subsequent drafts of the manuscript and have approved the submitted version. All authors have agreed both to be personally accountable for the author's own contributions and to ensure that questions related to the accuracy or integrity of any part of the work, even ones in which the author was not personally involved, are appropriately investigated, resolved, and the resolution documented in the literature. 


\section{Funding}

This research receives external funding from the Norwegian Physiotherapy Association. Internal founding is provided by OsloMet. The funding bodies had no role in the design, data collection, data analysis, interpretation of the results or decision of publication.

\section{Availability of data and materials}

The datasets used and/or analysed during the current study are available from the corresponding author on reasonable request.

\section{Ethics approval and consent to participate}

The Regional Committee for Medical Research Ethics in South East Norway approved the study (Ref. 2015/2432), and the trial was registered at ClinicalTrials.gov in September 2016, NCT02905383. All participants provided written informed content, and the project was conducted according to the World Medical Association Declaration of Helsinki.

\section{Consent for publication}

Not applicable.

\section{Competing interests}

The authors declare that they have no competing interests.

\section{Author details}

${ }^{1}$ Institute of Physiotherapy, OsloMet - Oslo Metropolitan University (OsloMet), PO Box 4, St. Olavs Plass, 0130 Oslo, Norway. ${ }^{2}$ Diakonhjemmet Hospital, PO Box 23, Vinderen, 0319 Oslo, Norway. ${ }^{3}$ School of Health and Life Sciences, Glasgow Caledonian University, Glasgow, UK. ${ }^{4}$ Department of Clinical Science, University of Bergen, Bergen, Norway. ${ }^{5}$ Faculty of Health Sciences, OsloMet - Oslo Metropolitan University (OsloMet), Oslo, Norway.

\section{Received: 29 June 2020 Accepted: 13 October 2020}

Published online: 11 November 2020

\section{References}

1. Organization WH. Good health adds life to years. In: Global brief for World Health Day, vol. 2012; 2012.

2. Duan-Porter W, Vo TN, Ullman K, Langsetmo L, Strotmeyer ES, Taylor BC, et al. Hospitalization-associated change in gait speed and risk of functional limitations for older adults. J Gerontol A Biol Sci Med Sci. 2019;74(10):1657-63.

3. Mattison M. In: Schmader KE, Auerbach A, editors. UpToDate Hospital management of older adults: In; 2019.

4. Brovold T, Skelton DA, Sylliaas H, Mowe M, Bergland A. Association between health-related quality of life, physical fitness, and physical activity in older adults recently discharged from hospital. J Aging Phys Act. 2014;22(3):405.

5. Asmus-Szepesi KJE, de Vreede PL, Flinterman LE, Nieboer AP, Bakker TJEM, Borsboom GJJM, et al. Prognosis of hospitalised older people with different levels of functioning: a prospective cohort study. Age Ageing. 2013;42(6): 803-9.

6. Garber CE, Blissmer B, Deschenes MR, Franklin BA, Lamonte MJ, Lee IM, et al. American College of Sports Medicine position stand. Quantity and quality of exercise for developing and maintaining cardiorespiratory, musculoskeletal, and neuromotor fitness in apparently healthy adults: guidance for prescribing exercise. Med Sci Sports Exerc. 2011;43(7):1334-59.

7. Liu CJ, Latham NK. Progressive resistance strength training for improving physical function in older adults. Cochrane Database Syst Rev. 2009;3: CD002759.

8. Howe TE, Rochester L, Neil F, Skelton DA, Ballinger C. Exercise for improving balance in older people. Cochrane Database Syst Rev. 2011;11:CD004963.

9. Powell KE, King AC, Buchner DM, Campbell WW, DiPietro L, Erickson Kl, et al. The Scientific Foundation for the physical activity. J Phys Act Health. 2019; 16:1-11.

10. Gillison FB, Skevington SM, Sato A, Standage M, Evangelidou S. The effects of exercise interventions on quality of life in clinical and healthy populations; a meta-analysis. Soc Sci Med. 2009;68(9):1700-10.

11. Organization WH. Information sheet: global recommendations on physical activity for health 65 years and above, vol. 2019; 2011.

12. Deer RR, Goodlett SM, Fisher SR, Baillargeon J, Dickinson JM, Raji M, et al. A randomized controlled pilot trial of interventions to improve functional recovery after hospitalization in older adults: feasibility and adherence. J Gerontol. 2018;73(2):187-93.
13. Gill TM, Allore HG, Holford TR, Guo Z. Hospitalization, restricted activity, and the development of disability among older persons. JAMA. 2004;292(17):2115-24.

14. Boyd CM, Landefeld CS, Counsell SR, Palmer RM, Fortinsky RH, Kresevic D, et al. Recovery of activities of daily living in older adults after hospitalization for acute medical illness. J Am Geriatr Soc. 2008;56(12):2171-9.

15. Brovold T, Skelton DA, Bergland A. Older adults recently discharged from the hospital: effect of aerobic interval exercise on health-related quality of life, physical fitness, and physical activity. J Am Geriatr Soc. 2013;61(9):1580-5.

16. Dolansky MA, Zullo MD, Hassanein S, Schaefer JT, Murray P, Boxer R. Cardiac rehabilitation in skilled nursing facilities: a missed opportunity. Heart Lung. 2012:41(2):115-24

17. Gill T, Allore H, Gahbauer E, Murphy T. Change in disability after hospitalization or restricted activity in older persons. J Am Med Assoc. 2010; 304(17):1919-28.

18. McKelvie S, Hall AM, Richmond HR, Finnegan S, Lasserson D. Improving the rehabilitation of older people after emergency hospital admission. Maturitas. 2018;111:20-30.

19. Loyd C, Beasley TM, Miltner RS, Clark D, King B, Brown CJ. Trajectories of community mobility recovery after hospitalization in older adults. J Am Geriatr Soc. 2018;66(7):1399-403.

20. Verweij L, van de Korput E, Daams JG, Ter Riet G, Peters RJG, Engelbert RHH, et al. Effects of Postacute multidisciplinary rehabilitation including exercise in out-of-hospital settings in the aged: systematic review and meta-analysis. Arch Phys Med Rehabil. 2019;100(3):530-50

21. Sherrington C, Lord SR, Vogler CM, Close JC, Howard K, Dean CM, et al. A post-hospital home exercise program improved mobility but increased falls in older people: a randomised controlled trial. PLoS One. 2014;9(9):e104412.

22. de Vries NM, van Ravensberg CD, Hobbelen JSM, Olde Rikkert MGM, Staal JB, MWG N-v DS. Effects of physical exercise therapy on mobility, physical functioning, physical activity and quality of life in community-dwelling older adults with impaired mobility, physical disability and/or multi-morbidity: a meta-analysis. Ageing Res Rev. 2012;11(1):136.

23. Apóstolo J, Cooke R, Bobrowicz-Campos E, Santana S, Marcucci M, Cano A, et al. Effectiveness of interventions to prevent pre-frailty and frailty progression in older adults: a systematic review. JBI Database System Rev Implement Rep. 2018;16(1):140-232.

24. Schulz KF, Altman DG, Moher D, Group C. CONSORT 2010 statement: updated guidelines for reporting parallel group randomised trials. PLoS Med. 2010;7(3):e1000251

25. Guralnik JM, Simonsick EM, Ferrucci L, Glynn RJ, Berkman LF, Blazer DG, et al. A short physical performance battery assessing lower extremity function: association with self-reported disability and prediction of mortality and nursing home admission. J Gerontol. 1994:49(2):M85-94.

26. Fletcher GF, Ades PA, Kligfield P, Arena R, Balady GJ, Bittner VA, et al. Exercise standards for testing and training: a scientific statement from the American Heart Association. Circulation. 2013;128(8):873-934

27. Folstein MF, Folstein SE, McHugh PR. "mini-mental state". A practical method for grading the cognitive state of patients for the clinician. J Psychiatr Res. 1975:12(3):189-98.

28. Nilsson BB, Lunde P, Holm I. Implementation and evaluation of the Norwegian Ullevaal model as a cardiac rehabilitation model in primary care. Disabil Rehabil. 2017;41(4):1-8.

29. Littbrand $H$, Rosendahl E, Lindelof N, Lundin-Olsson L, Gustafson Y, Nyberg L. A high-intensity functional weight-bearing exercise program for older people dependent in activities of daily living and living in residential care facilities: evaluation of the applicability with focus on cognitive function. Phys Ther. 2006;86(4):489-98.

30. Littbrand $H$, Lindelöf $N$, Rosendahl E. The HIFE program: the high-intensity functional exercise program. Umea: Universität Umea; 2014.

31. Slade SC, Dionne CE, Underwood M, Buchbinder R. Consensus on exercise reporting template (CERT): explanation and elaboration statement. $\mathrm{Br}$ J Sports Med. 2016;50(23):1428-37.

32. Borg G. Perceived exertion as an indicator of somatic stress. Scand J Rehabil Med. 1970.

33. Ory M, Resnick B, Jordan PJ, Coday M, Riebe D, Ewing Garber C, et al. Screening, safety, and adverse events in physical activity interventions: collaborative experiences from the behavior change consortium. Ann Behav Med. 2005;29(Suppl):20-8.

34. Health TNDo. Øvelser for å forebygge fall - For deg som føler deg litt ustø når du går utendørs 2016 [updated 04/2016. Available from: https://helsenorge.no/ SiteCollectionDocuments/ntnu_fallforebygging_1_2016-ny2.pdf. 
35. Craig CL, Marshall AL, Sjostrom M, Bauman AE, Booth ML, Ainsworth BE, et al. International physical activity questionnaire: 12-country reliability and validity. Med Sci Sports Exerc. 2003;35(8):1381-95.

36. Bergh. Short Physical Performance battery (SPPB) Norwegian Version Available at: 2013.

37. Crapo RO, Casaburi R, Coates AL, Enright PL, Maclntyre NR, McKay RT, et al. ATS statement: guidelines for the six-minute walk test. Am J Respir Crit Care Med. 2002;166(1):111-7.

38. Halsaa KE, Brovold T, Graver V, Sandvik L, Bergland A. Assessments of interrater reliability and internal consistency of the Norwegian version of the berg balance scale. Arch Phys Med Rehabil. 2007:88(1):94-8.

39. Bohannon RW. Test-retest reliability of measurements of hand-grip strength obtained by dynamometry from older adults: a systematic review of research in the PubMed database. J Frailty Aging. 2017;6(2):83-7.

40. Ware JE Jr, Sherbourne CD. The MOS 36-item short-form health survey (SF-36). I. Conceptual framework and item selection. Med Care. 1992;30(6):473-83.

41. Perera S, Mody SH, Woodman RC, Studenski SA. Meaningful change and responsiveness in common physical performance measures in older adults. J Am Geriatr Soc. 2006;54(5):743-9.

42. Jakobsen JC, Gluud C, Wetterslev J, Winkel P. When and how should multiple imputation be used for handling missing data in randomised clinical trials - a practical guide with flowcharts.(Report). BMC Med Res Methodol. 2017;17(1).

43. Cohen J. Statistical power analysis for the behavioral sciences. Hillsdale: L. Erlbaum Associates; 1988

44. Bergland A, Strand BH. Norwegian reference values for the short physical. performance battery (SPPB): the Tromso study. BMC Geriatr. 2019;19(1):216.

45. Richards DA, Hallberg IR. Complex interventions in health : an overview of research methods. London, England. New York: Routledge; 2015.

46. Norman GR, Sloan JA, Wyrwich KW. Interpretation of changes in healthrelated quality of life: the remarkable universality of half a standard deviation. Med Care. 2003;41(5):582-92.

47. Jacobsen EL, Bye A, Aass N, Fossa SD, Grotmol KS, Kaasa S, et al. Norwegian reference values for the short-form health survey 36 : development over time. Qual Life Res. 2018:27(5):1201-12.

48. Buurman BM, Hoogerduijn JG, de Haan RJ, Abu-Hanna A, Lagaay AM, Verhaar HJ, et al. Geriatric conditions in acutely hospitalized older patients: prevalence and one-year survival and functional decline (geriatric conditions: prevalence and outcomes). PLoS One. 2011;6(11):e26951.

49. Pacala JT, Judge JO, Boult C. Factors affecting sample selection in a randomized trial of balance enhancement: the FICSIT study. J Am Geriatr Soc. 1996:44(4):377-82.

50. McKelvie S, Hall A, Richmond H, Finnegan S, Lasserson D. Rehabilitation for older people after emergency hospital admission: a systematic review. Physiotherapy. 2017;103:e19-20

\section{Publisher's Note}

Springer Nature remains neutral with regard to jurisdictional claims in published maps and institutional affiliations.

Ready to submit your research? Choose BMC and benefit from:

- fast, convenient online submission

- thorough peer review by experienced researchers in your field

- rapid publication on acceptance

- support for research data, including large and complex data types

- gold Open Access which fosters wider collaboration and increased citations

- maximum visibility for your research: over $100 \mathrm{M}$ website views per year

At $\mathrm{BMC}$, research is always in progress.

Learn more biomedcentral.com/submissions 